\title{
Preconcentration and Separation of Trace As(III) and Sb(III) by Carbon Nanofibers Loaded With Ammonium Pyrroinedithiocarbamate Prior to ICP-MS Determination
}

\author{
Shizhong Chen•, Yuanyuan He, Yan Zhang, and Dengbo Lu \\ College of Chemical and Environmental Engineering, Wuhan Polytechnic University, \\ 68 Xuefu South Road Changqing Garden, Wuhan 430023, P.R. China
}

\section{INTRODUCTION}

Owing to the rapid growth in technology and the industries, the elemental levels in the environment have received considerable attention in recent years. Arsenic (As) and antimony ( $\mathrm{Sb})$ are treated as potential chemical hazards by the World Health Organization (1). There is much epidemiological evidence that shows that arsenic causes diseases such as skin, lung, bladder, and kidney cancers $(2,3)$. Excessive exposure to antimony may lead to a wide variety of adverse health effects, including respiratory tract irritation, dermatitis, conjunctivities, suppuration of the nasal septum, gastritis, and cellular damage in the lung, heart, and kidneys (4). Consequently, a reliable and accurate analytical procedure is necessary for the determination of trace/ultra-trace arsenic and antimony in environmental and biological samples.

Current analytical techniques for the determination of trace/ultratrace elements mainly include atomic absorption spectrometry, inductively coupled plasma atomic emission spectrometry, inductively coupled plasma mass spectrometry (ICP-MS), isotope dilution spark mass spectrometry, neutron activation analysis, and differential pulse anodic strpping voltammetry (5-9). Although some of these techniques are very sensitive, there is still the need for a separation and preconcentration procedure before the

*Corresponding autbor.

E-mail: chenshizbong62@163.com

Fax: + 862783956442

\section{ABSTRACT}

Based on carbon nanofibers (CNFs) loaded with ammonium pyrroinedithiocarbamate (APDC) as an adsorbent, a novel method is described for the preconcentration, separation, and determination of trace As(III) and Sb(III) by inductively coupled plasma mass spectrometry (ICP-MS). The adsorption behavior of the analytes on CNFs-APDC was investigated under dynamic conditions. The effects of $\mathrm{pH}$, sample flow rate and volume, elution solution and interfering ions on the preconcentration and separation of the analytes were examined in detail. The adsorption capacity of CNFs-APDC for As(III) and Sb(III) was $3.6 \mathrm{mg} \mathrm{g}^{-1}$ and $2.8 \mathrm{mg} \mathrm{g}^{-1}$, respectively. Under the optimum conditions, the detection limit $(3 \sigma)$ of this method was $0.065 \mathrm{ng}$ $\mathrm{mL}^{-1}$ of As(III) and $0.012 \mathrm{ng} \mathrm{mL}^{-1}$ of $\mathrm{Sb}$ (III), and the relative standard deviation (RSD) was 3.1\% and $5.4 \%$, respectively $(n=9$, $\mathrm{c}=1.0 \mathrm{ng} \mathrm{mL}^{-1}$ ). This method was applied to the determination of trace $\mathrm{As}$ (III) and $\mathrm{Sb}$ (III) in natural water samples with recoveries of $95.3-104 \%$. In order to validate this method, a certified reference material of human hair (GBW 07601) was analyzed, and the determined values were in good agreement with the certified values.

measurement step due to matrix effects and low levels of the analytes in real samples. To date, the widely used techniques for the separation and preconcentration of trace/ultra-trace elements include coprecipitation, solvent extraction, cloud point extraction, solid phase extraction (SPE), ion exchange, hydride generation, and chromatography (10-16). Among these techniques, SPE for the preconcentration and separation of trace elements has achieved increasing application because of its simplicity, speed, high enrichment factors, rapid phase separation, and ability to combine with different detection techniques.

In the SPE technique, selection of an appropriate sorbent is of importance for the elaboration of an analytical procedure. Thus, the development of a new adsorbent material with high selectivity and sensitivity is forever of interest to analysts $(17,18)$. Recently, a nanostructure material as a new adsorbent for the preconcentration and separation of substances has drawn growing attention in the analytical sciences (19-26). As a novel and interesting material, carbon nanofibers (CNFs) have been used for hydrogen storage and the separation/preconcentration of trace elements due to their high chemical stability and large specific surface area (27-30). Some investigations showed that an important strategy for elemental enrichment is the incorporation of complexing reagents in solid supports (31-34). To the best of our knowledge, however, studies on the separation and preconcentration of trace elements have received little attention using CNFs loaded with APDC.

In this study, a novel method was developed for the separation and preconcentration of trace As(III) and $\mathrm{Sb}$ (III) by a microcolumn 
packed with immobilized APDC on CNFs before ICP-MS determination. This method validation was performed and applied for the determination of trace As(III) and $\mathrm{Sb}$ (III) in environmental and biological samples.

\section{EXPERIMENTAL}

\section{Instrumentation}

A Thermo Elemental X-7 ICP-MS (Thermo Elemental Corporation, USA), equipped with a standard low-volume glass impact-bead spray chamber, a concentric glass nebulizer and Fassel-type torch, was used in this work. The samples and standards were spiked with $2.0 \mathrm{ng}$ $\mathrm{mL}^{-1}$ of indium internal standard before measurement. The ion lens settings, nebulizer flow rate, and torch position of the instrument were optimized daily in order to obtain the maximum ${ }^{115}$ In count rate. The operating parameters for ICP-MS are listed in Table I.

A Model HL-2 peristaltic pump (Shanghai Qingpu Huxi Instrument Factory, P.R. China), coupled to a self-made polytetrafluoroethylene (PTFE) microcolumn $(20 \mathrm{~mm} \times 3.0$ mm i.d.) packed with CNFs-APDC, was used for the preconcentration and separation process. A minimum length of PTFE tubing with an i.d. of $0.5 \mathrm{~mm}$ was used for all connec- tions. The $\mathrm{pH}$ values of the solutions were controlled with a $\mathrm{pH}$ meter (Thermo Orion Corporation, USA), supplied with a combined electrode. A Model Ethos T microwave system (Milestone, Italy) was used for sample digestion.

\section{Standard Solutions and Reagents}

The As(III) and Sb(III) stock solutions (1.0 mg mL $\mathrm{mL}^{-1}$ ) were purchased from the National Analysis Center of Iron \& Steel (Beijing, P.R. China). The working solutions of the analytes were prepared by mixing and diluting the stock solutions. All other reagents used were of ultrapure or at least of analytical grade. High-purity water obtained from a Milli-Q®A-10 system (Millipore Corporation, USA) was used throughout this work. The $\mathrm{pH}$ values of the solution were adjusted by adding an appropriate amount of $\mathrm{HCl}$. The CNFs were kindly provided by the Shenyang Metal Institute of the Chinese Academy (Shenyang, P.R. China).

\section{Preparation of Microcolumn with APDC}

The microcolumn was prepared by placing $20 \mathrm{mg}$ of CNFs into an empty conical column using the dry packing method. To avoid loss of CNFs, a small amount of quartz

TABLE I

ICP-MS Operating Parameters

\begin{tabular}{ll}
\hline Plasma Power & $1.3 \mathrm{~kW}$ \\
Plasma Argon Flow Rate & $14.5 \mathrm{~L} \mathrm{~min}^{-1}$ \\
Auxiliary Argon Flow Rate & $0.71 \mathrm{~L} \mathrm{~min}^{-1}$ \\
Nebulizer Argon Flow Rate & $0.94 \mathrm{~L} \mathrm{~min}{ }^{-1}$ \\
Sampler Orifice (nickel) & $1.1 \mathrm{~mm}$ \\
Skimmer Orifice (nickel) & $0.7 \mathrm{~mm}$ \\
Acquisition Mode & Peak-jumping \\
Number of Sweep & 100 \\
Dwell Time & $10 \mathrm{~ms}$ \\
Acquisition Time & $40 \mathrm{~s}$ \\
Number of Measurements per Peak & 3 \\
Isotopes & $75 \mathrm{As},{ }^{122} \mathrm{Sb}$, and ${ }^{115} \mathrm{In}$ \\
\hline
\end{tabular}




\section{A Aomic}

\section{Recommended Procedure}

Aliquots of 20-mL solutions containing As(III) and $\mathrm{Sb}$ (III) were prepared, and the $\mathrm{pH}$ was adjusted to the desired value with $\mathrm{HCl}$. The solution was passed through the microcolumn by using a peristaltic pump at a desired flow rate. Afterwards, the retained metal ions were eluted with $0.6 \mathrm{~mol} \mathrm{~L}^{-1} \mathrm{NaOH}$ solution. The analytes in the effluents were determined by ICP-MS. The column could be used repeatedly after regeneration with $0.6 \mathrm{~mol} \mathrm{~L}^{-1}$ $\mathrm{NaOH}$ solution and high purity water, respectively.

\section{RESULTS AND DISCCUTION}

\section{Influence of pH on Adsorption}

In the SPE procedure, the $\mathrm{pH}$ value of the aqueous sample plays an important role with respect to the adsorption of the analytes on the CNFs-APDC. In order to evaluate the effect of $\mathrm{pH}$, a series of sample solutions was adjusted to the $\mathrm{pH}$ range of $1.0-10$ with $\mathrm{HCl}$ and processed according to the recommended procedure. The effect of $\mathrm{pH}$ value on the recoveries of the analytes was investigated. The recoveries were calculated based on the difference between the amounts of the analytes in the starting sample and in the solution flowing out from the column. The results shown in Figure 1 indicate that quantitative recoveries (>90\%) for $\mathrm{As}$ (III) and $\mathrm{Sb}(\mathrm{III})$ were obtained in the $\mathrm{pH}$ range of 2.0 to 4.0. Thus, all other experiments in this work were carried out at $\mathrm{pH} 3.0$.

\section{Choice of Eluent}

The choice of eluent is very important for the successful coupling of a microcolumn preconcentration system to the ICP-MS. From Figure 1, it can be seen that the adsorption of the analytes on the CNFs-APDC is negligible at $\mathrm{pH}>10$. The reason for this may be that extra $\mathrm{NaOH}$ results in the decomposition of the As(III)/Sb(III)-APDC complex and the formation of soluble $\mathrm{AsO}_{3}{ }^{3-} / \mathrm{SbO}_{3}{ }^{3-}$. Thus, various concentrations of the $\mathrm{NaOH}$ solutions were studied for desorption of the retained analytes from the microcolumn. The results in Table II show that $0.4 \mathrm{~mol} \mathrm{~L}^{-1} \mathrm{NaOH}$ was sufficient for the quantitative elution of the analytes (>90\%). As a result, a $0.6 \mathrm{~mol} \mathrm{~L}^{-1} \mathrm{NaOH}$ solution was selected for the elution of As(III) and $\mathrm{Sb}$ (III) in the following experiments.

In addition, the effect of eluent volume on the recoveries of the analytes was also investigated with $0.6 \mathrm{~mol} \mathrm{~L}^{-1} \mathrm{NaOH}$ solution (Table III). The experimental results demonstrated that quantitative recoveries (>90\%) were obtained with $1.5 \mathrm{~mL}$ of $0.6 \mathrm{~mol} \mathrm{~L}^{-1} \mathrm{NaOH}$ solution. Taking the required sampling volume for ICP-MS into account, a $2.0-\mathrm{mL}$ eluent volume was adopted for this work.

\section{Effect of Flow Rate of Sample Solution}

Retention of the analytes on the adsorbent depends on the flow rate of the sample solution. Therefore, the flow rate of the sample solution was optimized in the range of 0.2 and $2.0 \mathrm{~mL} \mathrm{~min}^{-1}$ by passing $20 \mathrm{~mL}$ of solution through the microcolumn with a peristaltic pump. The experimental results in Figure 2 show that quantitative recoveries of the studied ions (>90\%) were obtained in the flow rate range of 0.2-1.2 $\mathrm{mL} \mathrm{min}^{-1}$. However, the recoveries of the analytes will decrease by further increasing the flow rate above $1.2 \mathrm{~mL} \mathrm{\textrm {min } ^ { - 1 }}$ because of a decrease in adsorption kinetics. In this work, a flow rate of $1.2 \mathrm{~mL} \mathrm{~min}^{-1}$ was used for subsequent determination.

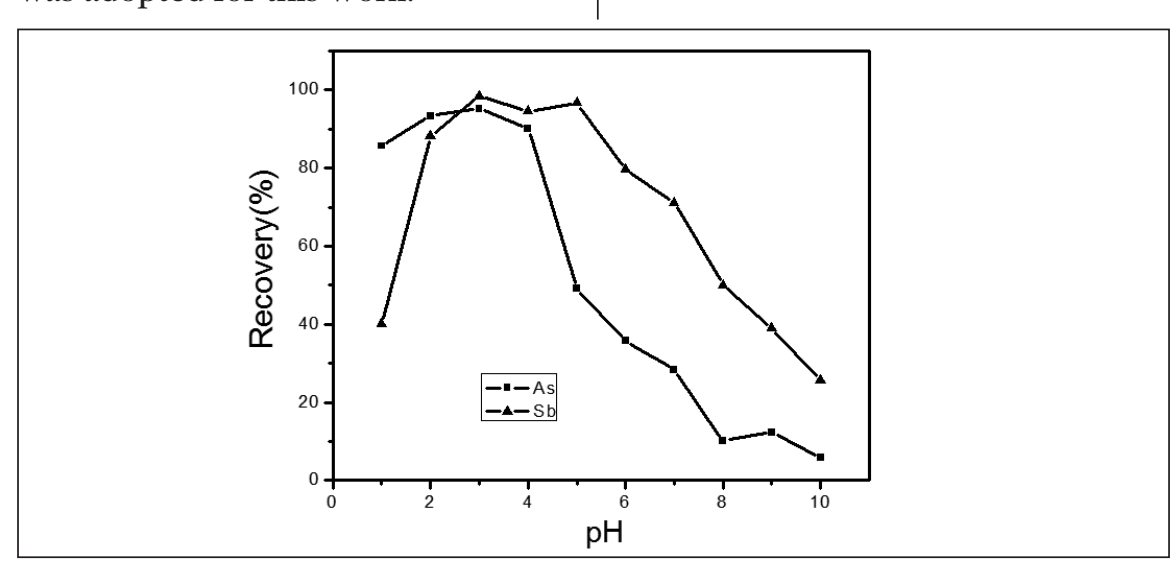

Fig. 1. Effect of $p H$ on the adsorption of As(III) and Sb(III) on CNFs-APDC.

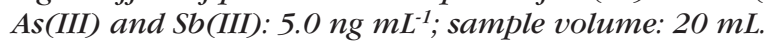

TABLE II

Effect of Eluent Concentration on the Recovery of Analytes

\begin{tabular}{|c|c|c|}
\hline \multirow{2}{*}{$\begin{array}{l}\text { Concentration } \\
\left(\mathrm{NaOH}, \mathrm{mol} \mathrm{mL}^{-1}\right)\end{array}$} & \multicolumn{2}{|c|}{ Recovery (\%) } \\
\hline & As(III) & $\mathrm{Sb}(\mathrm{III})$ \\
\hline 0.1 & 42.3 & 50.2 \\
\hline 0.2 & 68.9 & 71.3 \\
\hline 0.4 & 90.1 & 91.4 \\
\hline 0.6 & 98.3 & 98.7 \\
\hline 0.8 & 96.5 & 96.5 \\
\hline
\end{tabular}

TABLE III Effect of Eluent Volume on the Recovery of Analytes

\begin{tabular}{ccc}
\hline $\begin{array}{c}\text { Eluent Volume } \\
(\mathrm{NaOH}, \mathrm{mL})\end{array}$ & \multicolumn{2}{c}{ Recovery(\%) } \\
As(II) & Sb(III) \\
\hline 0.5 & 50.9 & 45.9 \\
1.0 & 70.2 & 75.4 \\
1.5 & 91.2 & 92.3 \\
2.0 & 96.4 & 94.7 \\
2.5 & 97.3 & 98.3 \\
3.0 & 95.8 & 95.7 \\
\hline
\end{tabular}




\section{Effect of Sample Volume}

High preconcentration factors are neccesary for the determination of lower analyte levels in real environmental and biological samples. Hence, the effect of sample volume on the recovery of the analytes was examined in the range of $20-250 \mathrm{~mL}$ sample volume containing $10 \mathrm{ng}$ of the analytes. The above sample solutions were passed through the microcolumn at an optimum flow rate according to the recommended procedure. As can be seen in Figure 3 , the analytes could be recovered quantitatively (>90\%) up to $150 \mathrm{~mL}$ of sample solution. Because the elution volume was $1.5 \mathrm{~mL}$ of 0.6 mol L ${ }^{-1} \mathrm{NaOH}$ solution, an enrichment factor of 100 was achieved in this work.

\section{Interference Study}

The effects of common coexisting ions on the adsorption of the analytes were investigated. The tolerance limit of coexisting ions is defined as the largest amount that makes the recovery of the analyte less than $90 \%$. In the present experiments, $5.0 \mathrm{ng} \mathrm{mL}^{-1}$ solutions of the analytes containing the added interfering ions were treated according to the recommended procedure. Table IV shows that the coexisting foreign ions did not interfere in the determination within the range of their amounts tested.

\section{Adsorption Capacity}

The adsorption capacity was investigated by a method provided in the literature (35). Aliquots of $100 \mathrm{~mL}$ of a series of concentrations (1.0-10 $\mathrm{g} \mathrm{mL}^{-1}$ ) were adjusted to the appropriate $\mathrm{pH}$, then preconcentrated and eluted. The amount of metal ions adsorbed at each concentration level was determined. Breakthrough curves were obtained by plotting the metal ion concentrations $\left(\mu \mathrm{g} \mathrm{mL}^{-1}\right)$ versus the milligram of metal ions adsorbed on per gram of adsorbent. The adsorption capacity calculated from the breakthrough curve was 3.6 and $2.8 \mathrm{mg} \mathrm{g}^{-1}$ for As(III) and $\mathrm{Sb}(\mathrm{III})$, respectively.

TABLE IV Tolerance Limits of Coexisting Ions

\begin{tabular}{lr}
\hline $\begin{array}{l}\text { Coexisting } \\
\text { Ion }\end{array}$ & $\begin{array}{r}\text { Concentration } \\
\text { Ratio }\end{array}$ \\
\hline $\mathrm{Na}^{+}, \mathrm{K}^{+}$ & 10,000 \\
$\mathrm{Ca}^{2+}, \mathrm{Mg}^{2+}$ & 5000 \\
$\mathrm{Al}^{3+}, \mathrm{Fe}^{3+}$ & 200 \\
$\mathrm{SiO}_{3}{ }^{2-}, \mathrm{SO}_{4}{ }^{2-}, \mathrm{PO}_{4}{ }^{3-}$ & 2000 \\
\hline${ }^{\mathrm{a}} \mathrm{Concentration}_{\text {ratio: }}$ Foreign \\
ion/determined ion.
\end{tabular}

\section{Column Reuse}

In order to examine the longterm stability of the microcolumn, it was subjected to successive adsorption and desorption cycles by passing $20 \mathrm{~mL}$ of the solutions containing the analytes through the column. The stability and potential regeneration of the column were assessed by monitoring the changes in the recoveries of the analytes. The column can be reused after regeneration with $3.0 \mathrm{~mL}$ of 0.6 mol L ${ }^{-1} \mathrm{NaOH}$ solution and $20 \mathrm{~mL}$ deionized water, respectively, and is stable up to 50 adsorption-elution cycles without any obvious decrease in the adsorption capacity and the recovery for the analytes.

\section{Analytical Performance}

The reproducibility of the preconcentration was evaluated by passing $20 \mathrm{~mL}$ of standard solution of the analytes through the microcolumn and repeating the procedure nine times. The obtained relative standard deviation (RSD) of $\mathrm{As}$ (III) and $\mathrm{Sb}$ (III) $\left(\mathrm{c}=1.0 \mathrm{ng} \mathrm{\textrm {mL } ^ { - 1 } )}\right.$ was $3.1 \%$ and $5.4 \%$, respectively. The detection limit, defined as the concentration that produces a signal equivalent to three times the standard deviation of nine measurements of the blank, was $0.065 \mathrm{ng}$ $\mathrm{mL}^{-1}$ and $0.012 \mathrm{ng} \mathrm{mL}^{-1}$ for As(III) and $\mathrm{Sb}(\mathrm{III})$, respectively.

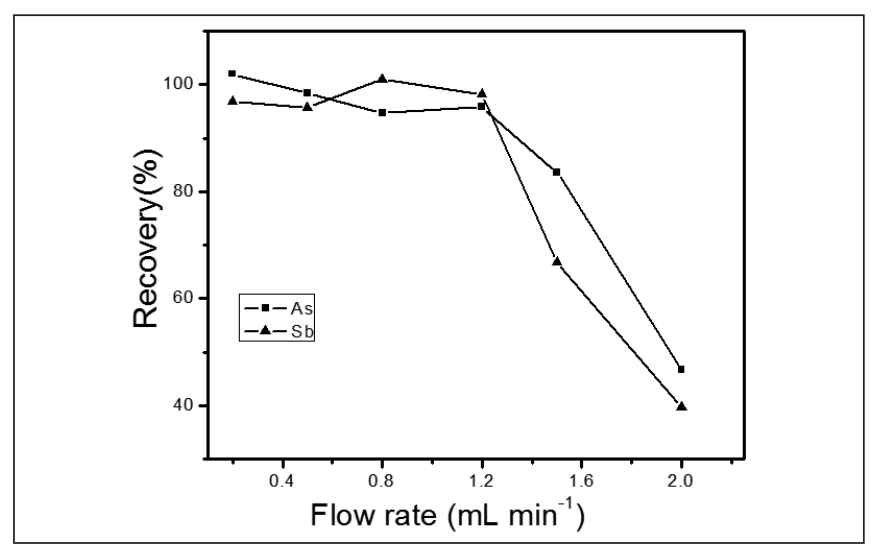

Fig. 2. Effect of sample flow rate on the recovery of As(III)

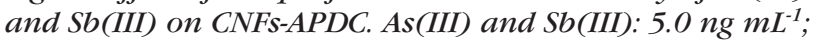
pH=3.0; sample volume: $20 \mathrm{~mL}$.

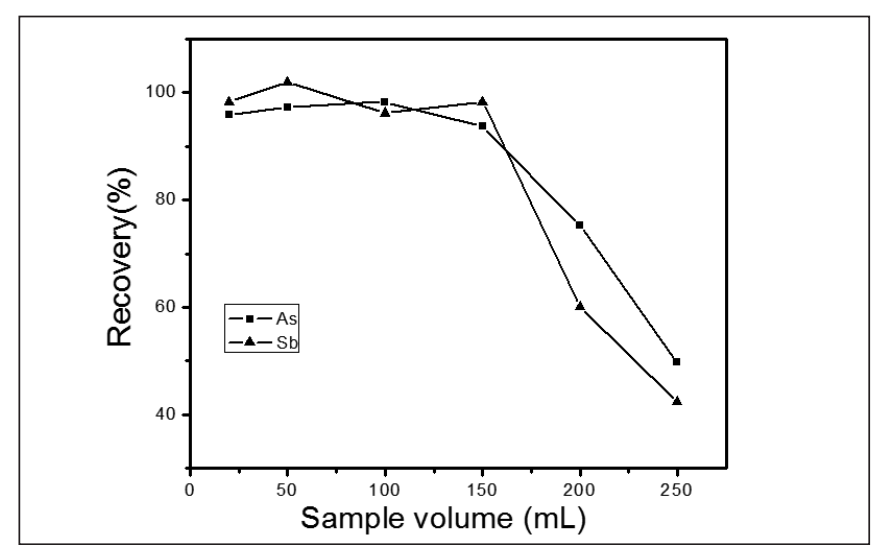

Fig. 3. Effect of sample volume on the recovery of As(III) and Sb(III) on CNFs-APDC. pH: 3.0; sample volume: $20 \mathrm{~mL}$; As(III) and Sb(III): $10 \mathrm{ng}$. 


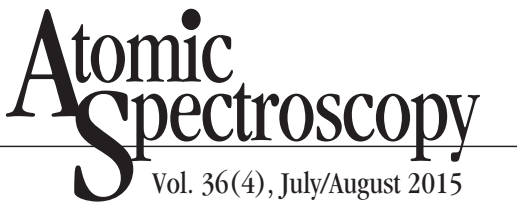

TABLE $\mathrm{V}$

Analytical Results of the Analytes in Natural Water Sample

\begin{tabular}{lccc}
\hline Element & $\begin{array}{c}\text { Added } \\
\left(\mathrm{ng} \mathrm{mL}^{-1}\right)\end{array}$ & $\begin{array}{c}\text { Found }^{\mathrm{a}} \\
\left(\mathrm{ng} \mathrm{mL}^{-1}\right)\end{array}$ & $\begin{array}{c}\text { Recovery } \\
(\%)\end{array}$ \\
\hline As(III) & 0 & $0.38 \pm 0.04$ & - \\
& 2.0 & $2.31 \pm 0.15$ & 96.5 \\
& 3.0 & $3.51 \pm 0.26$ & 104 \\
$\mathrm{Sb}$ (III) & 0 & $0.091 \pm 0.008$ & - \\
& 2.0 & $2.13 \pm 0.17$ & 102 \\
& 3.0 & $2.95 \pm 0.21$ & 95.3 \\
\hline
\end{tabular}

${ }^{\text {a }}$ Mean value \pm standard deviation, $n=3$.

\section{Sample Analysis}

In order to establish the validity of this method, the analytes were determined in a natural water sample and a biological reference material (GBW 07601 Human Hair). The obtained results are summarized in Tables V and VI, respectively. As can be seen, the determined values were in good agreement with the certified values, and the recoveries of the analytes were reasonable for trace analysis and ranged from $95.3-104 \%$.

\section{CONCLUSION}

In this work, an effective procedure for the preconcentration and separation of trace As(III) and $\mathrm{Sb}(\mathrm{III})$ in environmental and biological samples is described using a microcolumn packed with CNFsAPDC, followed by ICP-MS analysis. The adsorption behavior of the analytes was investigated in detail. The analytes were retained in the $\mathrm{pH}$ range of 2.0-4.0, and desorbed quantitatively with $1.5 \mathrm{~mL}$ of 0.6 mol L $\mathrm{L}^{-1} \mathrm{NaOH}$ solution. In addition, no carryover was observed in the next analysis. The analytes could be concentrated 100 times within a short time and recovered with high precision. The adsorption capacity for As(III) and Sb(III) was $3.6 \mathrm{mg} \mathrm{g}^{-1}$ and $2.8 \mathrm{mg} \mathrm{g}^{-1}$, respectively. The experimental results show that this method is applicable for the determination of trace/ultratrace elements in natural water and hair samples.

\section{ACKNOWLEDGMENTS}

The authors are grateful to the Nature Science Foundation and the Education Department Foundation of Hubei Province in P.R. China for supporting this project.

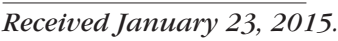

\section{REFERENCES}

1. S. Hu, X. Hu, H. Liu, L. Huang, and R. Liu, At. Spectrosc. 35(2), 90 (2014).

2. C. Liao, H.Shen, C. Chen, L. Hsu, T. Lin, S. Chen, and C. Chen, J. Hazard. Mater. 165(1-3), 652 (2009).

3. P.J. Mink, D.D. Alexander, L.M. Barraj, M.A. Kelsh, and J.S. Tsuji, Regul. Toxicol. Pharm. 52(3), 299 (2008).

4. M. Krachler, H. Emons, and J. Zheng, Trac trends Anal. Chem. 20, 79 (2001).

5. K.L. Mandiwana, N. Panichev, and S Panicheva, Food Chem. 129, 1839 (2011)

6. S. Chen, H. Zhang, and B. Ruan, At. Spectrosc. 30(4), 143 (2009).

7. S. Chen, S. Zhu, Y. He, and D. Lu, Food Chem. 150, 254 (2014).

8. R.E. Sturgeon, S.S. Berman, J.A.H. Desaulniers, A.P. Mykytituk, J.W. Mclaren, and D.S. Russell, Anal. Chem. 52, 1585 (1980).
TABLE VI

Analytical Results of the Analytes in Standard Reference Material of Human Hair

Mean value \pm standard deviation, $n=3$.
Certified

$\left(\mu \mathrm{g} \mathrm{g}^{-1}\right)$

$\left(\mu \mathrm{g} \mathrm{g}^{-1}\right)$

$0.28 \pm 0.04$

$0.095 \pm 0.012$ 
24. M. Behbahani, A. Bagheri, M. Taghizadeh, M. Salarian, O. Sadeghi, L. Adlnasab, and K. Jalali, Food Chem. 138(2-3), 2050 (2013).

25. S. Chen, X. Guo, Y. Zhang, and D. Lu, Anal. Meth. 6, 3668 (2014).

26. Y. Wu, J. Zhang, J. Liu, Z. Deng, M. Han, F. Jiang, D. Wang, H. Wang, and $\mathrm{H}$. Yuan, At. Spectrosc.32(1), 41 (2011).

27. A. Chambers, C. Park, R. T. K. Baker, and N. M. Rodriguez, J. Chem. Phys. B 102(22), 4253 (1998).

28. Y. He, S. Chen, X. Zhou, and X. Wang, At. Spectrosc. 33(4), 117 (2012).

29. S. Chen, M. Xiao, D. Lu, and X. Zhan, Rapid Comm. Mass Spectrom. 21, 2524 (2007).

30. S. Chen, X. Zhan, D. Lu, and C. Liu, At. Spectrosc. 29(4), 124 (2008).

31. E.M. Soliman, M.B. Saleh, and S.A. Ahmed, Anal. Chim. Acta 523, 133 (2004).

32. M. Tuzen, K.O. Saygi, and M. Soylake, J. Hazard. Mater. 632, 152 (2008).

33. M. Ghaedi, A. Shokrollahi, A.H. Kianfar, A. Pourfarokhi, N. Khanjari, A.S. Mirsadeghi, and M. Soylak, J. Hazard. Mater. 162, 1408 (2009).

34. G. Kaya, I. Akdeniz, and M. Yaman, At. Spectrosc. 29(4), 150 (2009).

35. A. Maqieira, H.AM. Elmahadi, and R. Puchades, Anal. Chem. 66, 3632 (1994). 